\title{
Neutron imaging investigation of fossil woods: non-destructive characterization of microstructure and detection of in situ changes as occurring in museum cabinets
}

\author{
Giliane P. Odin ${ }^{1,2}$, Véronique Rouchon ${ }^{2}$, Frédéric Ott ${ }^{3}$, Natalie Malikova ${ }^{1}$, Pierre Levitz ${ }^{1}$, and Laurent J. Michot ${ }^{1}$ \\ ${ }^{1}$ Laboratoire PHENIX, UMR 8234, Sorbonne Universités, UPMC, CNRS, Paris, 75005, France \\ ${ }^{2}$ Centre de recherche sur la conservation, USR 3224, Sorbonne Universités, MNHN, MCC, CNRS, Paris, 75005, France \\ ${ }^{3}$ Laboratoire Léon Brillouin, UMR 12, CEA CNRS, Gif-sur-Yvette, 91190, France
}

Correspondence to: Giliane P. Odin (giliane.odin@gmail.com) and Laurent J. Michot (laurent.michot@upmc.fr)

Received: 21 October 2016 - Revised: 29 January 2017 - Accepted: 30 January 2017 - Published: 28 February 2017

\begin{abstract}
This paper discusses the applicability of neutron imaging techniques for probing the internal microstructure of several fossil woods upon wetting and drying, two phenomena occurring in museum cabinets and endangering the fossil woods. Investigations were carried out using lignites (fossil woods) from two French localities (Rivecourt, Parisian Basin, Oise - Paleogene; Angeac, Aquitanian Basin, Charente - Cretaceous), which present different macroscopic behavior upon drying. Thanks to the high sensitivity of neutrons to hydrogen content, it was possible to track water diffusion through $3 \mathrm{~mm}$ thick samples and to follow in situ changes related to either supply or withdrawal of water without any special preparation and in a relevant time range (from $1 \mathrm{~min}$ to a few hours). Classical image analysis allows discriminating between the behavior of the two fossil woods with regard to their interaction with water. Further analysis based on a Fourier transform of projection images provides additional information regarding the existence of large pores in one of the samples. Differences in pore network and internal structures have important mechanical consequences as one of the samples retains its integrity upon drying, whereas the other one shatters into pieces. A better understanding of the underlying processes will clearly require multi-scale analyses, using additional techniques that could probe the materials at a lower scale. Such a combination of multi-scale analyses should provide valuable information for a better conservation of wood remnants, which is crucial for both paleobotanical research and museum exhibits.
\end{abstract}

\section{Introduction}

Paleobotany relies on the study of various fossil woods, from giant redwoods trunks to coal seeds. Among them, lignites (a low-rank coal) are particularly difficult to conserve. Some authors have reported their spontaneous combustion $(\mathrm{Ohm}$, 2012). This particular reactivity is associated with their high moisture content and high porosity, as well as with the presence of reactive $\mathrm{C}$ sites such as carbonyl that are activated due to the catalyzing action of mineral impurities (Takarada et al., 1985; Ohm, 2012; Kabir et al., 2013). Regarding this latter point, the presence of iron sulfides has a significant negative impact. Indeed, iron sulfides are extremely sensitive to oxidation, leading to undesirable growth of sulfate efflorescence, weakening the structure of the fossil wood. In view of the importance of lignites in (i) paleoenvironments and paleoclimate reconstruction and (ii) phylogenetic studies, their conservation represents a major issue and clearly deserves further study.

In the whole process of conservation, drying is a crucial step. It is unavoidable considering the change in conditions experienced by fossil woods. Indeed, before excavation, fossil woods are in mostly anoxic conditions, protected from oxygen by several meters of sediment. Upon excavation, fossil woods are exposed to both oxygen and dry air and thus undergo change due to a combination of chemical and mechanical processes. Consequently, when this step is performed quickly without any caution, the woods tend to shrink and crack, losing their coherence. Such a problem is challenging not only for paleontological woods but also for archeological waterlogged woods that may contain iron sulfides because 
of bacteriological activity (Wetherall et al., 2008; Fors et al., 2012). Drying issues are also of concern for present woods, even though they are free of iron sulfides. Depending on their industrial end use, they need to be dried, from an initial water content of $50 / 200 \%$ wt to a final one around $8 / 15 \% \mathrm{wt}$ (Ståhl et al., 2004; Rémond et al., 2007). This provokes mechanical stress and shrinkage, issues that are relatively well managed thanks to numerous works that have investigated the drying of present woods to reduce both costs and environmental impact while increasing wood quality.

Most of these works have focused on the simulation of wood physicochemical property changes (Spolek and Plumb, 1981; Perré and Turner, 2002; Tahmasebi et al., 2012) and the effect of various drying parameters (temperature, moisture, ventilating power; Rémond et al., 2007; Klavina et al., 2015; Zadin et al., 2015). Simulations have highlighted the complexity of the material (heterogeneities upon species, material anisotropy) and the important role of numerous physical properties in the drying process. Thibeault et al. (2010) succeeded in building a 3-D model predicting the final state of wood samples submitted to precise drying, thanks to a precise matching between computational and experimental results.

In fossil woods the inner morphology of the initial wood is to some extent preserved, thus allowing the identification of species. Yet the material itself shares many common features with coals for which structural parameters, such as porosity and permeability, have been extensively studied (Parkash, 1986; Levine, 1996; Levine et al., 1993; Calo and Hall, 2004; Flores, 2013). Structural parameters determined by intrusive techniques investigating the physical-structural properties (gas adsorption, mercury intrusion) are to some extent comparable to those determined with non-intrusive techniques (Okolo et al., 2015). Although intrusion and adsorption techniques are cheaper and easier to perform, they are not suitable for studying fragile materials such as fossil woods. On these materials, non-intrusive techniques appear more adequate. For instance, imaging and scattering techniques using X-rays or neutrons, such as small-angle X-ray scattering (SAXS) and small-angle neutron scattering (SANS), offer promising alternatives for analyzing the porosity of carbonrich materials (Calo and Hall, 2004).

Concerning imaging, several techniques have recently been developed to access the 3-D structure of complex materials at the nanoscale (Brisard et al., 2012; Bae et al., 2015), microscale (Levitz et al., 2012) or macroscale (Gimenez et al., 2016). Appropriate mathematical treatment of images can provide quantitative data on the structural topology of the material (Allman et al., 2000; Levitz, 2007). In addition, it was recently shown that projection images can also be used to derive scattering curves that are equivalent to those obtained by small-angle scattering techniques (Brisard et al., 2012; Michot et al., 2013; Bae et al., 2015). This is particularly relevant to the study of complex materials as scattering curves are sensitive to the geometrical properties of both heterogeneities and interfaces (Levitz, 2007).

Our work aims at better understanding the structure of fossil woods and its evolution upon drying and wetting. For all the reasons mentioned above, we opted for combining imaging techniques at various scales and small-angle scattering techniques to reach a multi-scale characterization of the materials structural features. The present paper focuses on one aspect of this experimental strategy: it presents the application of neutron imaging to lignites (fossil woods) that come from two different locations and behave differently upon drying.

The use of neutrons bears several advantages. Firstly, neutrons, as non-charged particles, penetrate deep into materials. It is thus possible to analyze large samples using neutronic techniques. Secondly, neutrons are particularly sensitive to hydrogen atoms, which are strong scatterers. Consequently, neutrons interact strongly with hydrogenated samples such as organic matter and water. These two features were recently used to obtain precise structural radiographic images of a wooden artifact (Lehmann and Mannes, 2012). Thirdly, neutron scattering is isotope-dependent; in particular, hydrogen and deuterium have scattering lengths of opposite signs, which allows adapting "at will" the contrast by using mixtures of deuterated and hydrogenated samples, such as mixtures of $\mathrm{D}_{2} \mathrm{O}$ and $\mathrm{H}_{2} \mathrm{O}$.

In the present study we take advantage of the strong interaction of neutron with hydrogen to visualize in situ and real-time changes occurring in fossil woods upon drying and wetting, at a millimetric to centimetric scale. We will show that neutron imaging experiments provide opportunities (i) to follow water diffusion/withdrawal across the sample, leading to permeability and porosity network images; (ii) to perform a quantitative analysis of wood heterogeneities through a dedicated image treatment; and (iii) to understand differences in drying behavior of fossil woods. This can provide valuable information for adapting the conservation protocols that could be applied, especially soon after excavation.

\section{Experimental}

\subsection{Material}

Fossil woods, mainly composed of lignite, were obtained from two French localities: Rivecourt, Parisian Basin, Oise (Paleogene; Hauterivian-Barremian, $\sim 122 / 114 \mathrm{Ma}$ ), and Angeac, Aquitanian Basin, Charente (Cretaceous; Paleocene, $\sim 65 / 53 \mathrm{Ma}$ ).

X-ray diffraction and Mössbauer spectrometry were applied to freshly excavated samples, indicating for both woods the presence of pyrite and excluding other types of iron sulfides (not shown). Angeac samples contain large pyritic clusters of macroscopically visible (which are thus avoidable) and more sparsely microscopic crystals. In contrast, Rive- 
court samples contain numerous micrometric pyrite crystals, invisible to the naked eye and randomly distributed in the bulk of the wood. For the experiment, samples were visually chosen to be as free of pyrite as possible. From a mechanical point of view, Rivecourt samples are friable and those from Angeac are strong.

When drying is performed with no particular caution, Angeac samples tend to break down, while Rivecourt ones crumble. In both sample types, the cell structures seem to be partly preserved.

For water absorption measurements, samples dried at $0 \%$ relative humidity $(\mathrm{RH})$ in non-anoxic closed vessels over several days (from 7 to 50) were considered. Conversely, waterlogged samples were used for drying measurements. They were kept in closed vials full of water and sediment to minimize sample-air contact between excavation and experiment.

\subsection{Neutron experiments}

Neutron experiments were carried out on the IMAGINE beamline at the LLB (Laboratoire Léon Brillouin, Gifsur-Yvette, France). The flux was about $2 \times 10^{7}$ neutrons $\mathrm{cm}^{-2} \mathrm{~s}^{-1}$ for polychromatic neutrons with wavelengths ranging between 3 and $15 \AA$ and a ratio length of the neutron guide over beam aperture of 250 (Fig. 1a). The resolution was close to $100 \mu \mathrm{m}$, with a pixel size of $50 \mu \mathrm{m}$ and a field of view of $8 \times 8 \mathrm{~cm}$. One radiographic scan typically lasts $40 \mathrm{~s}$.

Both radiographic and tomographic scans were performed on the materials, but the present paper deals with the analysis by means of radiography only. Drying and sorption experiments were performed on samples placed vertically, i.e., along the wood fibers' main axis. For sorption, dry samples were placed in an aluminum cup filled with approximately $5 \mathrm{~mm}$ of water. Aluminum wires were used to vertically maintain the samples (Fig. 1b). For desorption, an aluminum base was placed in the analysis tube, and samples were piled above the plug and wedged with aluminum foils. A flow of argon was supplied to the samples by a system directly positioned on top of the tube and without contact with the samples (Fig. 1c).

To optimize contrast on images, different sample thicknesses were tested, ranging from 2 to $7 \mathrm{~mm}$. The best results were obtained for wood thickness of ca. $3 \mathrm{~mm}$. In such conditions, both wet and dry samples can be successfully imaged as dry samples are absorbing enough, while waterlogged ones do not absorb neutrons too strongly. Appropriate image contrast could then be obtained for a wide range of water contents.

\subsection{Software and data exploitation}

Images were treated using Image $\mathbf{J}$ by subtracting the background obtained by measuring air in the same acquisition conditions as the samples. The images were then cropped to define proper regions of interest (ROIs). The greyscale ob-
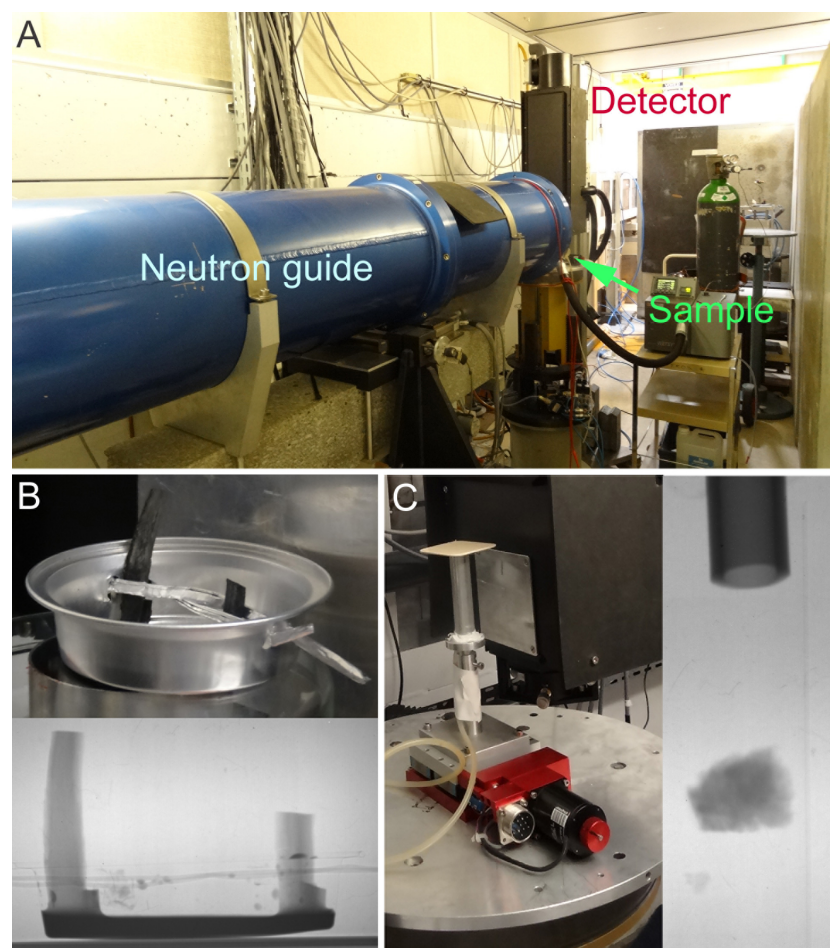

Figure 1. (a) Picture of neutron guide through experimental chamber. (b) Sorption experiment setup and radiographic image obtained. Wood samples were placed in an aluminum cup filled with water. Water appears dark, while aluminum is transparent to neutrons. (c) Desorption experiment setup and radiographic image obtained. Wood samples were wrapped in aluminum foils and placed in a tube, with direct air input (plastic tube, on top).

tained image was then treated according to procedures previously described (Brisard et al., 2012) to derive small-angle scattering (SAS) curves. In short, in view of the high penetration depth of neutrons, neutron projection images take into account the 3-D organization of the investigated material. Using the Fourier slice theorem (Kak and Slaney, 2001), it is possible by fast Fourier transform to derive, for a statistically isotropic medium, the small-angle scattering curve of the object. The extension of the SAS pattern is then defined by application of Shannon's theorem (Kak and Slaney, 2001): $q_{\max }=\frac{\pi}{\text { pixel size }}$ and $q_{\min }=\frac{2 \pi}{\min \left(L_{x}, L_{y}\right)}$, where $L_{x}$ and $L_{y}$ are the $x$ and $y$ global size of the ROI. In the present case $q_{\min }$ is of the order of $10^{-4} \mu \mathrm{m}^{-1}$. For comparison purposes, the curves were divided by the invariant that is written as Eq. (1):

$$
\int_{q_{\min }}^{q_{\max }} q^{2} I(q) \mathrm{d} q .
$$

Using such a transformation, the normalized intensity can be expressed in $\mu \mathrm{m}^{3}$. 


\section{Results and discussion}

\subsection{Water sorption experiments}

Direct visual assessment of radiographic images reveals the different behavior of Angeac and Rivecourt samples upon absorption. For Angeac samples, a comparison between images taken before and after sorption experiments (Fig. 2) does not reveal any striking change in absorption. Furthermore, after 90 min, the samples still appear dry. In contrast, Rivecourt samples already display a quick darkening for short imbibition times. As neutrons are extremely sensitive to water, more quantitative information can be obtained by plotting the grey levels' evolution through time in a given zone of the sample. The grey levels represent the number of neutrons detected after crossing the sample, and these decrease with increasing absorption. For well-calibrated samples, such a measurement could even be used to directly measure a sorption isotherm as calibration with pure water was carried out during the run. Unfortunately, wood samples are highly variable morphologically, and defining their exact thickness has proved to be impossible. Still, as shown in Fig. 3, analyzing the grey levels' evolution through time confirms visual observations. Indeed, for Rivecourt samples (Fig. 3a), the average grey levels decrease rapidly at first and then remain almost constant, whereas for the Angeac sample (Fig. 3b) the decrease is much slower. In this case, the latest values still exhibit a slow decrease, which suggests that hydration of the Angeac sample is not finished and would require a much longer time to complete. Plotting the results after normalization by the initial value (Fig. 3c) clearly shows that water uptake on Rivecourt samples is much more important than on those of Angeac for similar durations.

More information can be obtained by plotting the evolution of grey levels as a function of the square root of time. When such a treatment is implemented (Fig. 4) at least two linear regimes can be observed with a crossover, the location of which depends on the investigated fossil wood. For Rivecourt the crossover is located at times around $200 \mathrm{~s}$ (Fig. 4a), whereas for Angeac the corresponding value is around $900 \mathrm{~s}$ (Fig. 4b).

By applying Washburn equation Eq. (2),

$x^{2}=\frac{\gamma \cos \theta R}{2 \eta} t$,

where $t$ is the time for a liquid of dynamic viscosity $\eta$ and surface tension $\gamma$ to penetrate a distance $x$ into a pore of $R$ radius, with $\theta$ the contact angle between wood and water and assuming $x \approx 3 \mathrm{~cm}$ (sample size) and a contact angle about $60^{\circ}$ for water on coal (Keller Jr., 1987); it yields pore sizes of $\sim 2$ and $1 \mu \mathrm{m}$ for Rivecourt and Angeac, respectively. Such values are obviously rough estimates considering the numerous approximations associated with the Washburn equation for complex materials such as fossil woods. It therefore appears that the differences in behavior between Angeac and
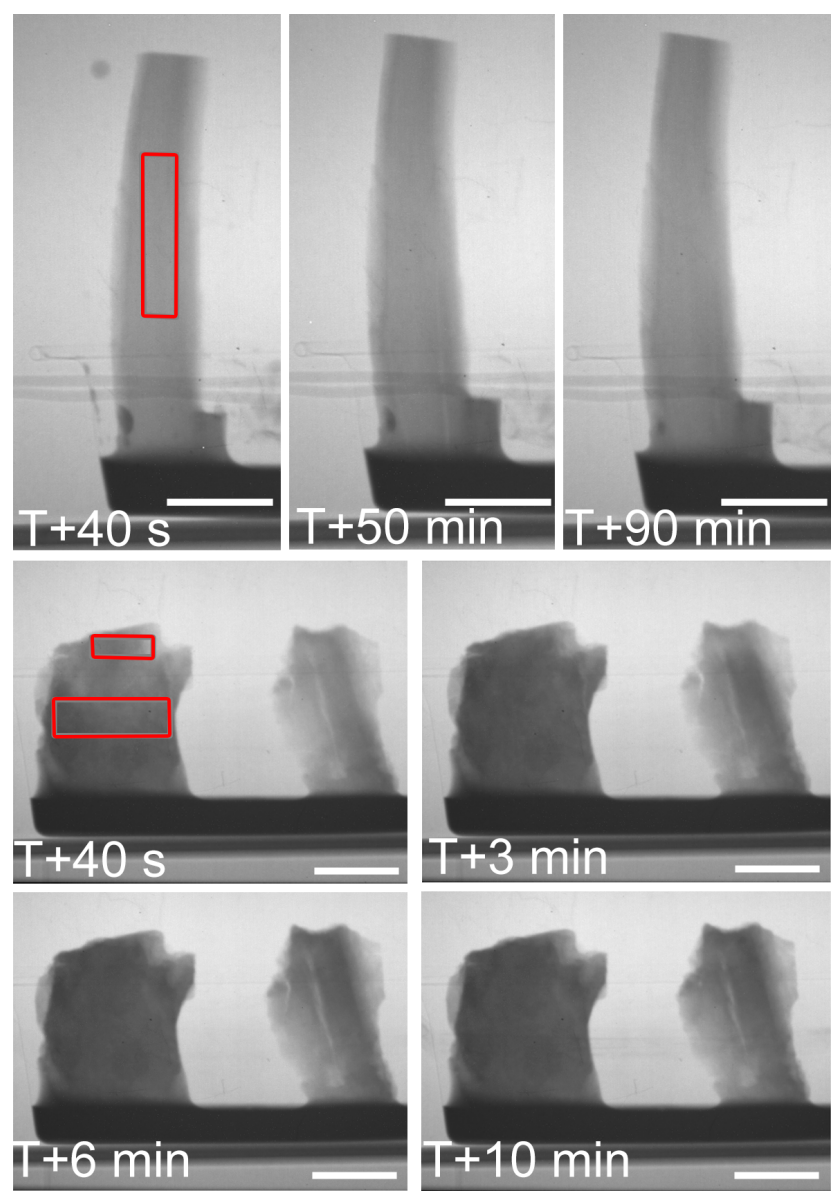

Figure 2. Radiographic images of sample upon sorption experiments. The three pictures on the top are from the Angeac sample, while the four on the bottom are that of Rivecourt. The scale represents $1 \mathrm{~cm}$. The marked areas correspond to the zones used for measuring average grey levels.

Rivecourt fossil woods may not be linked to pore structure at a small scale but could be linked to pore connectivity between various scales.

Further insight into these results can be obtained by plotting the evolution of the normalized intensity vs. $q$ obtained from treating neutron images (Fig. 5). For $q$ values less than $10^{-2} \mu \mathrm{m}^{-1}$, both fossil wood samples exhibit a decrease in intensity scaling as $q^{-4}$, indicating the presence of sharp density contrasts that do not change with time and therefore with increasing water contents. In contrast, the high $q$ region exhibits differences between both fossil woods. Indeed, that domain displays a modulation in both cases, centered around 2.8 and $2.4 \times 10^{-2} \mu \mathrm{m}^{-1}$ for Rivecourt (Fig. 5a) and Angeac (Fig. 5b) samples, respectively, with the modulation being wider for Rivecourt. In addition, after normalization, in the case of Angeac, the curves corresponding to different times are all superimposed, whereas in the case of Rivecourt, curves obtained for short imbibition times are clearly located above the others. This time range corresponds to the 

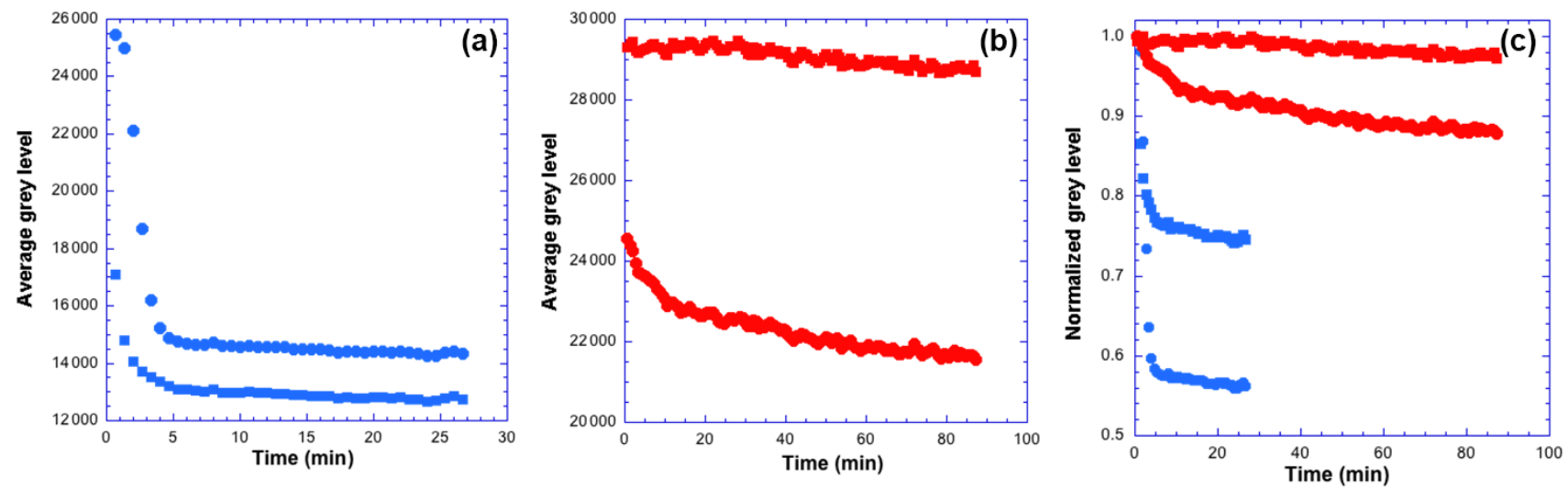

Figure 3. Evolution with time of average grey levels in the wetting experiment for (a) Rivecourt and (b) Angeac. (c) Evolution with time of normalized grey levels. Blue: Rivecourt sample. Red: Angeac sample (see text for details).
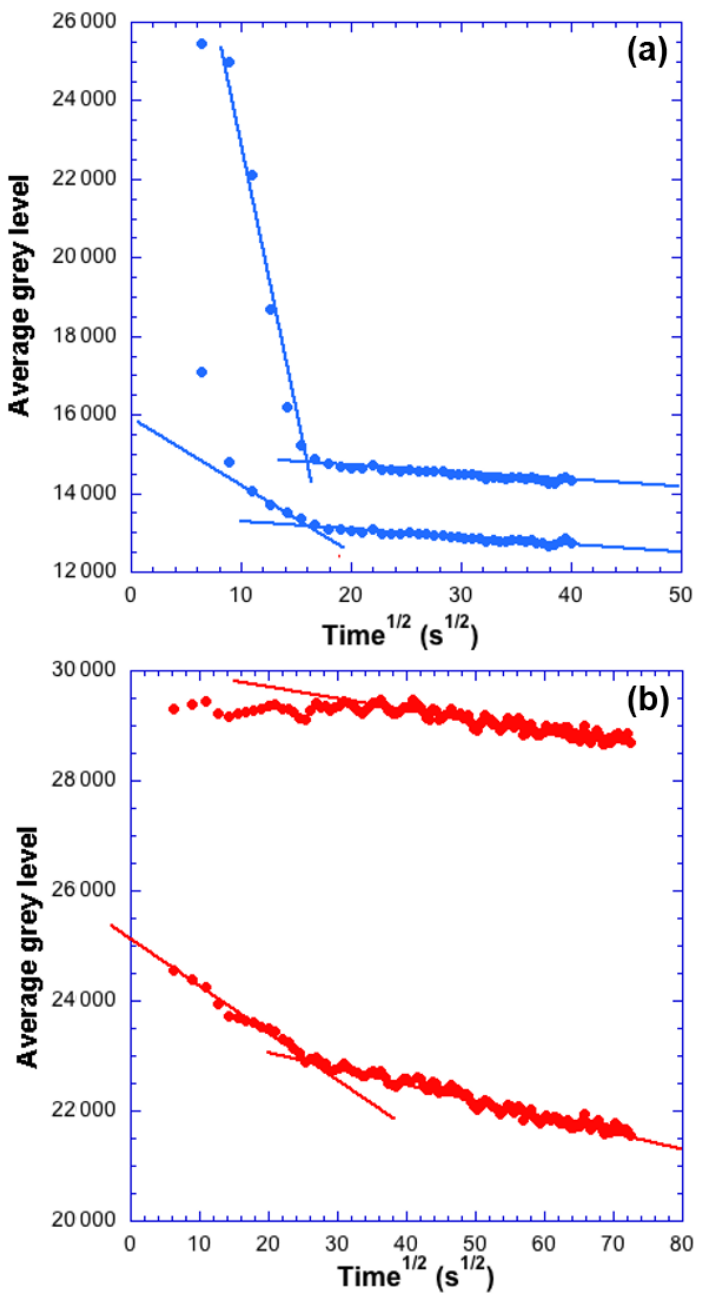

Figure 4. Evolution of average grey levels in the wetting experiments plotted as a function of the square root of time. (a) Rivecourt and (b) Angeac.
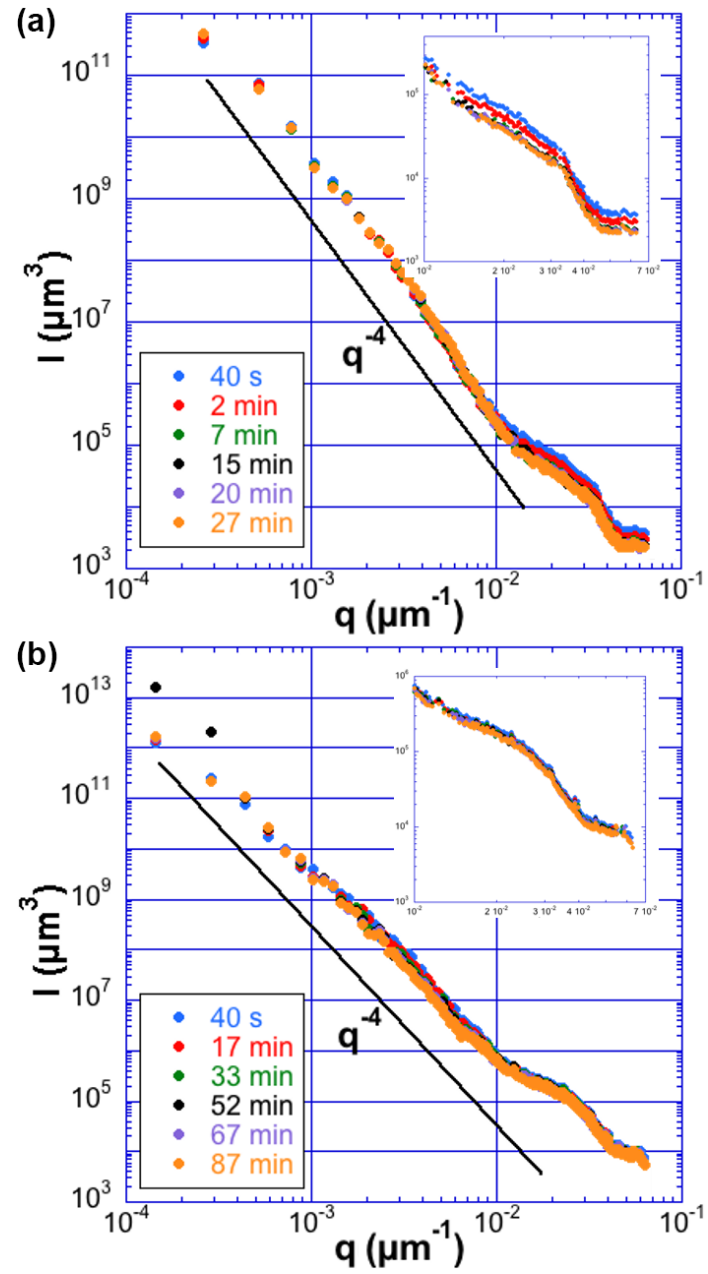

Figure 5. Evolution of $I(q)$ vs. $q$ upon wetting for (a) Rivecourt and (b) Angeac. The inset is a close-up of the area between 0.01 and $0.07 \mu \mathrm{m}^{-1}$. 


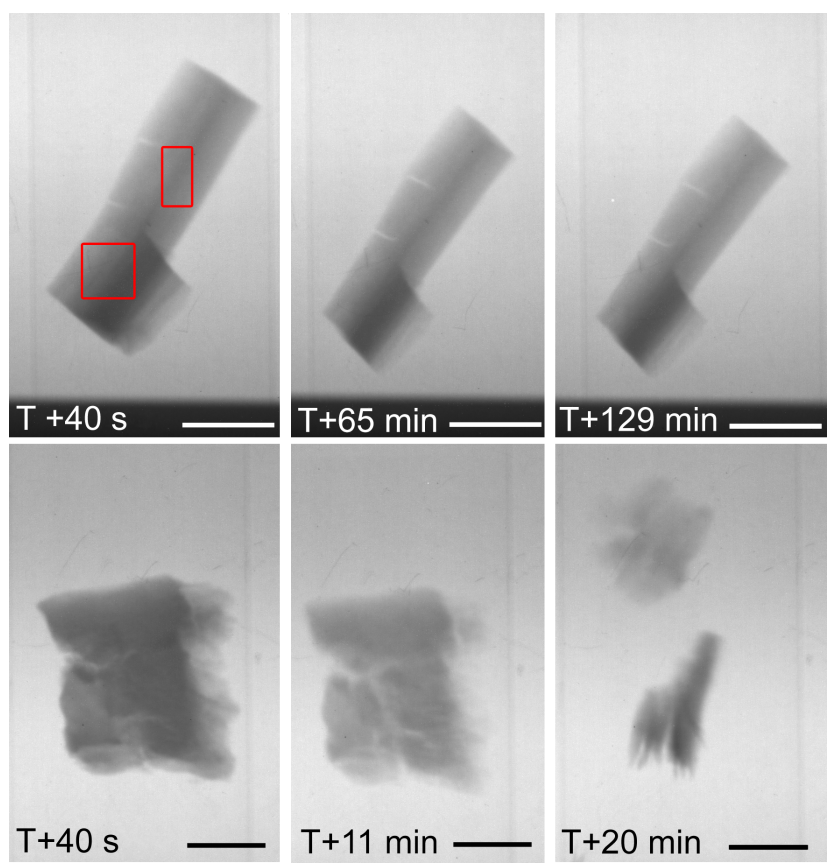

Figure 6. Radiographic images of sample upon desorption experiments. The Angeac sample is on the top, while the Rivecourt sample is on the bottom. The scale represents $1 \mathrm{~cm}$. The marked areas correspond to the zones used for measuring average grey levels. (For Rivecourt, it was done on another sample due to implosion of the sample.)

fast decrease in grey levels observed in Fig. 3a. Such an evolution may be linked to the filling of pores with sizes around $100 \mu \mathrm{m}\left(\pi / q\right.$ with $q$ around $\left.3 \times 10^{-2}\right)$ that would hence occur in Rivecourt samples and not in Angeac ones. This could well explain the strong water uptake observed at early stages for Rivecourt samples. It must be emphasized that such a feature would be extremely difficult to assess from classical image analysis but appears to be straightforward by using the Fourier slice theorem.

\subsection{Water desorption experiments}

It is clearly relevant to also analyze sample drying using the same tools. Indeed, as mentioned earlier, drying procedures are crucial in terms of conservation issues. In the present study, we applied rather drastic drying pathways. Angeac and Rivecourt samples were placed under a $10 \mathrm{~L} \mathrm{~min}^{-1}$ flux of dry argon gas. As shown in Fig. 6, this leads to very discriminating behavior between both samples. Indeed, Angeac samples display a significant retraction (around 20\%) but maintain their integrity during the whole drying sequence. In contrast, Rivecourt samples display a lesser retraction (around $10 \%$ ), but cracks rapidly appear on the samples, which shatter into pieces after approximately $20 \mathrm{~min}$ drying. It thus clearly appears that deformation alone cannot explain the fragile behavior of this sample as it exhibits less shrinking than the Angeac sample.

Analysis of the evolution through time of grey levels for both samples (Fig. 7) reveals various features. (i) For Rivecourt samples, the amplitude of the grey levels' variation upon drying (Fig. 7a) is similar to the one observed upon wetting. (ii) This is not the case for Angeac samples (Fig. 7b), where the total variation is much higher in the case of drying. This confirms what was said earlier, i.e., that wetting of Angeac samples was far from being complete. This is clearly confirmed by a comparison between Figs. $3 \mathrm{c}$ and $7 \mathrm{c}$ : the normalized grey levels are much less different between the two samples in the case of drying compared to wetting. (iii) When plotted as a function of the square root of times, the evolution of grey levels displays two linear ranges with a crossover located at similar times to those observed upon wetting (Fig. 4d), i.e., values around 300 and 900 s for Rivecourt and Angeac samples, respectively.

Figure 8 displays, for both samples, the evolution of $I(q)$ vs. $q$ obtained from image treatment. As previously noted, significant differences are observed between Angeac and Rivecourt samples. In the high $q$-range Rivecourt sample exhibits a significant increase in intensity with time (Fig. 8a), whereas a marginal difference is observed on Angeac sample even for longer durations (Fig. 8b). As already observed in the case of drying, it thus appears that the most striking differences between both fossil woods can be observed for equivalent sizes around $100 \mu \mathrm{m}$. The drying experiment evidences the strong consequences of such a difference on the mechanical integrity of the samples. Indeed, Angeac samples can be dried rather aggressively without breaking, in contrast with Rivecourt ones, which seem to be more fragile.

These differences could be tentatively assigned to differences in mineral content and nature of the organic material between fossil woods.

The nature and maturation degree of organic matter as defined by the so-called coal rank is known to strongly influence porosity (Flores, 2013), higher coal rank leading to a decrease in macroporosity and an increase in microporosity (Gan et al., 1972; Levine, 1996; Clarkson and Bustin, 1997). The two fossil woods studied in the present study belong to the lignite family and have relatively similar coal ranks. Still, Angeac samples were taken in the external areas of fossil woods where the initial ligneous wood structure is preserved. The inner part of the samples shows almost no structure and seems to be completely made of vitrinite, a particular set of characteristic macerals (the smallest organic compounds). This suggests a slightly more mature nature of Angeac samples than Rivecourt ones. This hypothesis would agree with the slower imbibition kinetics of Angeac wood compared to Rivecourt.

The mineral content, when significant (more than $7 \%$ according to Clarkson and Bustin, 1997), affects both porosity and permeability by closing the network, filling pores or replacing the maceral (Ward, 2002; Flores, 2013). Mineral- 

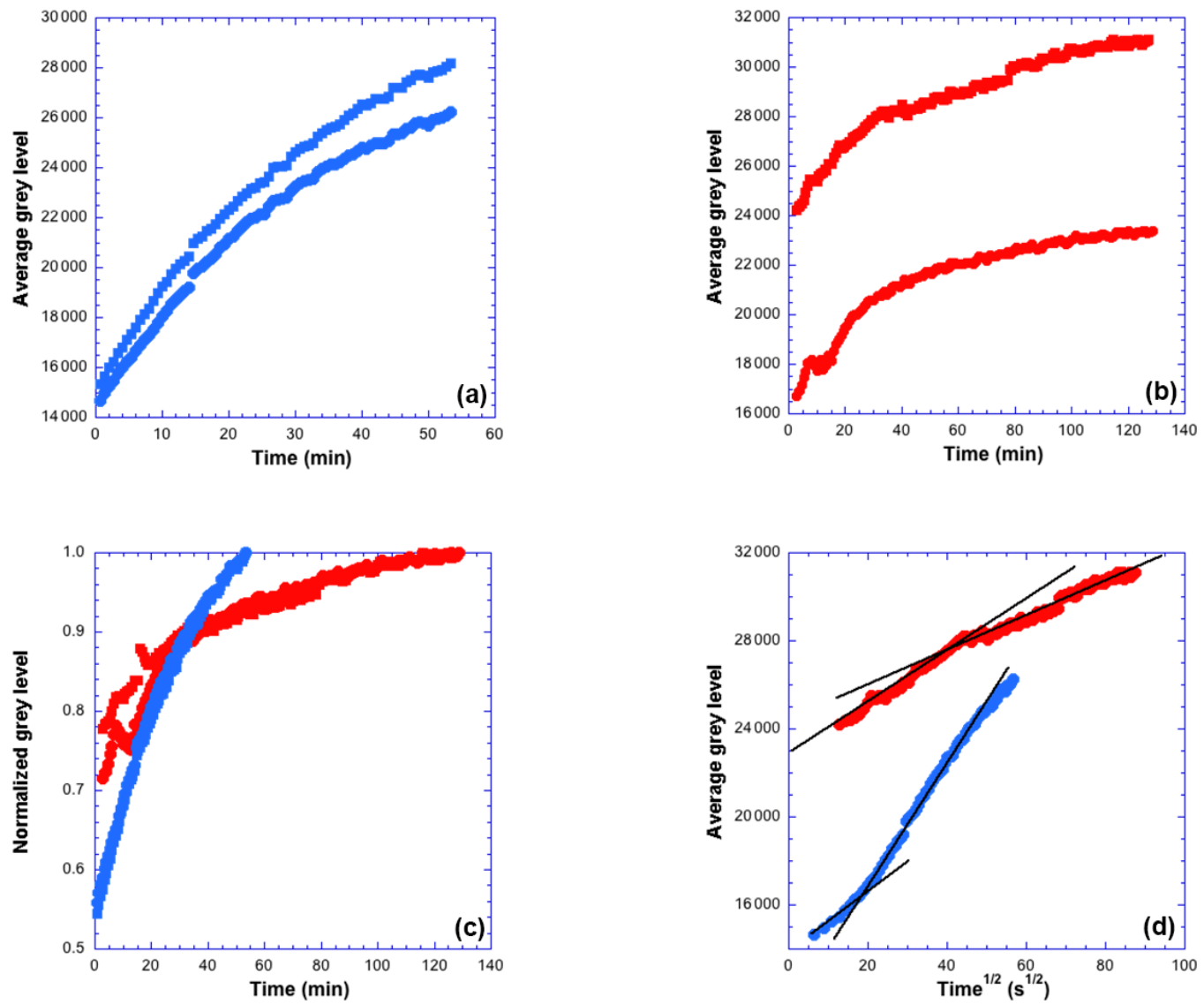

Figure 7. Evolution with time of average grey levels in the drying experiment for (a) Rivecourt and (b) Angeac. (c) Evolution with time of normalized grey levels. Blue: Rivecourt sample. Red: Angeac sample (see text for details). (d) Evolution of average grey levels in the drying experiments plotted as a function of the square root of time. Blue: Rivecourt sample. Red: Angeac sample.

filled structures are indeed clearly observed by $\mu \mathrm{CT}$ scan (Ramandi et al., 2016). In the case of the fossil woods studied here, pyrite is the main mineral phase to be considered. The presence of micrometric crystals may lead to a decrease in porosity, but it could also strongly affect the mechanical properties of the wood. Indeed, in his review, Flores (2013) clearly indicates that mineral matter controls the tendency of woods to shrink and swell. Furthermore, microheterogeneities (voids, inclusions, interfaces, etc.) are known to strongly affect mechanical properties (Toro, 2016; Wei, 2016), a feature that is well documented in the case of alloys where the presence of inclusions leads to the development of small cracks (El-Soudani and Pelloux, 1973). In the case studied here, the presence of numerous pyrite microcrystals could lead to the development of cracks (actually observed in Rivecourt) followed by the breakage of the material. It is worth mentioning that similar phenomena have already been described by Deevi for US lignites (Deevi and Suuberg, 1987).

\section{Conclusions}

This paper demonstrates how neutron imaging can provide relevant information about the behavior of fossil wood samples upon drying and wetting. Differences in behavior between two French fossil woods (Angeac, Aquitanian Basin - Cretaceous; Rivecourt, Parisian Basin - Paleogene) were able to be analyzed in detail by coupling classical image analysis, which is very sensitive to water content in the case of neutron images, and a Fourier transform analysis of projection images. This analysis successfully revealed differences between both fossil woods that could certainly not have been obtained otherwise.

The present study focuses on a relatively large analytical scale, i.e., from tenths of micrometers to centimeters. It should definitely be pursued by using techniques that allow for probing a material's structure at a lower scale. Xray tomography, X-ray microscopy and classical small-angle $\mathrm{X}$-ray and/or neutron small-angle scattering should then be applied to these types of materials. Such techniques would provide additional information on the spatial distribution and 

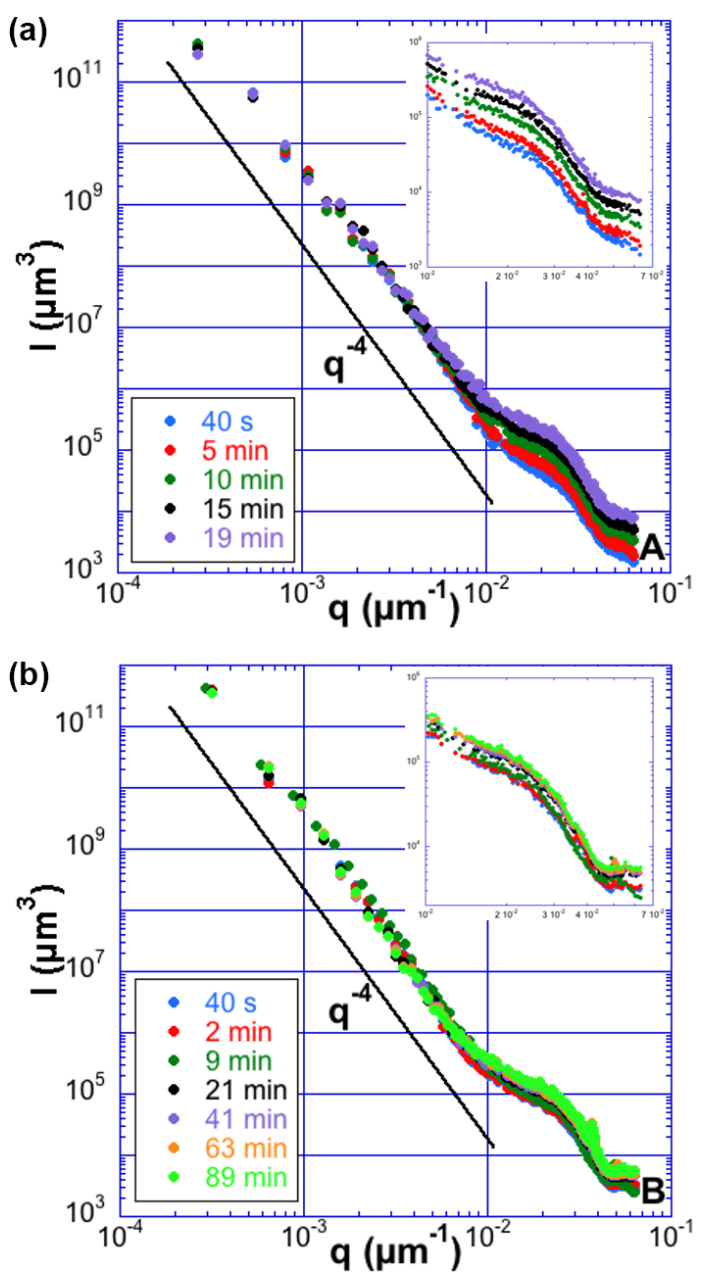

Figure 8. Evolution of $I(q)$ vs. $q$ upon drying for (a) Rivecourt and (b) Angeac. The inset is a close-up of the area between 0.01 and $0.07 \mu \mathrm{m}^{-1}$.

size distribution of mineral species within the fossil woods, which would be a stringent test of the assumption about the strong links between pyrite presence and drying behavior. Indeed, at present the better integrity of one kind of sample (excavated in Angeac) upon drying compared to the another (obtained in Rivecourt) is tentatively assigned to changes in the porous network and to the abundant presence, in one of the samples, of mineral inclusions whose interface with organic materials appears to weaken the structure. This will be the focus of future publications.

In terms of conservation issues, it is thus clear that probing the multiscale porosity of fossil woods is very relevant for understanding the behavior of specimens after their excavation, especially with regard to consequences of moisture variations in museum cabinets.

\section{Data availability}

The data have been deposited on DRYAD and are thus publicly accessible at doi:10.5061/dryad.4sn22 (Odin et al., 2017).

Competing interests. The authors declare that they have no conflict of interest.

Acknowledgements. Dario de Franceschi and Ronan Allain are gratefully acknowledged for providing samples and for discussions on fossil woods. This work was financially supported by Sorbonnes Universités (Convergence program, Science and Cultural Heritage, project no. 115218, ACOPAL).

Edited by: D. Korn

Reviewed by: two anonymous referees

\section{References}

Allman, B. E., McMahon, P. J., Nugent, K. A., Paganin, D., Jacobson, D. L., Arif, M., and Werner, S. A.: Imaging: Phase radiography with neutrons, Nature, 408, 158-159, doi:10.1038/35041626, 2000.

Bae, S., Taylor, R., Shapiro, D., Denes, P., Joseph, J., Celestre, R., Marchesini, S., Padmore, H., Tyliszczak, T., Warwick, T., Kilcoyne, D., Levitz, P., and Monteiro, P. J. M.: Soft X-ray Ptychographic Imaging and Morphological Quantification of Calcium Silicate Hydrates (C-S-H), J. Am. Cer. Soc., 98, 4090-4095, doi:10.1111/jace.13808, 2015.

Brisard, S., Chae, R. S., Bihannic, I., Michot, L. J., Guttmann, P., Thieme, J., Schneider, G., Monteiro, P. J. M., and Levitz, P.: Morphological quantification of hierarchical geomaterials by X-ray nano-CT bridges the gap from nano to micro length scales, Am. Mineral., 97, 480-483, doi:10.2138/am.2012.3985, 2012.

Calo, J. and Hall, P.: The application of small angle scattering techniques to porosity characterization in carbons, Carbon, 42, 1299_ 1304, doi:10.1016/j.carbon.2004.01.030, 2004.

Clarkson, C. and Bustin, R.: Variation in permeability with lithotype and maceral composition of Cretaceous coals of the Canadian Cordillera, Int. J. Coal Geol., 33, 135-151, doi:10.1016/S01665162(96)00023-7, 1997.

Deevi, S. and Suuberg, E.: Physical changes accompanying drying of western US lignites, Fuel, 66, 454-460, doi:10.1016/00162361(87)90147-5, 1987.

El-Soudani, S. M. and Pelloux, R. M.: Influence of inclusion content on fatigue crack, Metal. Trans., 4, 519-531, doi:10.1007/BF02648705, 1973.

Flores, R. M.: Coal and coalbed gas, Fueling the future, Elsevier Science, USA, 2013.

Fors, Y., Jalilehvand, F., Risberg, E. D., Björdal, C., Phillips, E., and Sandström, M.: Sulfur and iron analyses of marine archaeological wood in shipwrecks from the Baltic Sea and Scandinavian waters, J. Arch. Sci., 39, 2521-2532, doi:10.1016/j.jas.2012.03.006, 2012. 
Gan, H., Nandi, S., and Walter Jr., P. L.: Nature of the porosity in American coals, Fuel, 51, 272-277, doi:10.1016/00162361(72)90003-8, 1972.

Gimenez, L., Robert, S., Suard, F., and Zreik, K.: Automatic reconstruction of 3D building models from scanned 2D floor plans, Automat. Constr., 63, 48-56, doi:10.1016/j.autcon.2015.12.008, 2016.

Kabir, K. B., Hein, K., and Bhattacharya, S.: Process modelling of dimethyl ether production from Victorian brown coal - Integrating coal drying, gasification and synthesis processes, Comp. Chem. Eng., 48, 96-104, doi:10.1016/j.compchemeng.2012.08.008, 2013.

Kak, A. C. and Slaney, M.: Principles of Computerized Tomographic Imaging, Society for Industrial and Applied Mathematics, Philadelphia, 2001.

Keller Jr., D. V.: The contact angle of water on coal, Colloid. Surface, 22, 21-35, doi:10.1016/0166-6622(87)80003-3, 1987.

Klavina, K., Cinis, A., and Zandeckis, A.: Experimental Study on the Effects of Air Velocity, Temperature and Depth on Lowtemperature Bed Drying of Forest Biomass Residue, Energy Procedia, 72, 42-48, doi:10.1016/j.egypro.2015.06.007, 2015.

Lehmann, E. H. and Mannes, D.: Wood investigations by means of radiation transmission techniques, J. Cult. Herit., 13, S35-S43, doi:10.1016/j.culher.2012.03.017, 2012.

Lévine, J. R.: Geological Society, London, Special Publications, 109, 197-212, 1996.

Lévine, J. R., Law, B., and Rice, D.: AAPG Studies in Geology, Hydrocarbons from Coal, edited by: Law, B. E. and Rice, D. D., American Association of Petroleum Geologists, Chapter 3, 3977, 1993.

Levitz, P.: Toolbox for 3D imaging and modeling of porous media: Relationship with transport properties, Cement Concrete Res., 37, 351-359, doi:10.1029/2005WR004482, 2007.

Levitz, P., Tariel, V., Stampanoni, M., and Gallucci, E.: Topology of evolving pore networks, Eur. Phys. J. Appl. Phys., 60, 24202, doi:10.1051/epjap/2012120156, 2012.

Michot, L. J., Bihannic, I., Thomas, F., Lartiges, B. S., Waldvogel, Y., Caillet, C., Thieme, J., Funari, S. S., and Levitz, P.: Coagulation of Na-montmorillonite by inorganic cations at neutral $\mathrm{pH}$. A combined transmission X-ray microscopy, small angle and wide angle X-ray scattering study, Langmuir, 29, 3500-3510, doi:10.1021/la400245n, 2013.

Odin, G. P., Rouchon, V., Ott, F., Malikova, N., Levitz, P., and Michot, L. J.: Data from: Neutron imaging investigation of fossil woods: non-destructive characterization of microstructure and detection of in situ changes as occurring in museum cabinets, available at: doi:10.5061/dryad.4sn22, 2017.

Ohm, T.-I., Chae, J.-S., Lim, J.-H., and Moon, S.-H.: Evaluation of a hot oil immersion drying method for the upgrading of crushed low-rank coal, J. Mech. Sci. Technol., 26, 1299-1303, doi:10.1007/s12206-012-0210-4, 2012.

Okolo, G. N., Everson, R. C., Neomagus, H. W., Roberts, M. J., and Sakurovs, R.: Comparing the porosity and surface areas of coal as measured by gas adsorption, mercury intrusion and SAXS techniques, Fuel, 141, 293-304, doi:10.1016/j.fuel.2014.10.046, 2015.
Parkash, S. and Chakrabartty, S.: Microporosity in Alberta plains coals, Int. J. Coal Geol., 6, 55-70, doi:10.1016/01665162(86)90025-X, 1986.

Perré, P. and Turner, I. W.: A heterogeneous wood drying computational model that accounts for material property variation across growth rings, Chem. Eng. J., 86, 117-131, doi:10.1016/S13858947(01)00270-4, 2002.

Ramandi, H. L., Mostaghimi, P., Armstrong, R. T., Saadatfar, M., and Pinczewski, W. V.: Micro-CT image calibration to improve fracture aperture measurement, Int. J. Coal Geol., 154-155, 5768, doi:10.1016/j.csndt.2016.03.001, 2016.

Rémond, R., Passard, J., and Perré, P.: The effect of temperature and moisture content on the mechanical behaviour of wood: a comprehensive model applied to drying and bending, Eur. J. Mech. A-Solid, 26, 558-572, doi:10.1016/j.euromechsol.2006.09.008, 2007.

Spolek, G. and Plumb, O. A.: Capillary pressure in softwoods, Wood Sci. Technol., 15, 185-199, doi:10.1007/BF00353471, 1981.

Ståhl, M., Granström, K., Berghel, J., and Renström, R.:: Industrial processes for biomass drying and their effects on the quality properties of wood pellets, Biomass Bioenerg., 27, 621-628, doi:10.1016/j.biombioe.2003.08.019, 2004.

Tahmasebi, A., Yu, J., Hanand, Y., and Li, X.: A study of chemical structure changes of Chinese lignite during fluidized-bed drying in nitrogen and air, Fuel Process. Technol., 101, 85-93, doi:10.1016/j.fuproc.2012.04.005, 2012.

Takarada, T., Tamai, Y., and Tomita, A.: Reactivities of 34 coals under steam gasification, Fuel, 64, 1438-1442, doi:10.1016/00162361(85)90347-3, 1985.

Thibeault, F., Marceau, D., Younsiand, R., and Kocaefe, D.: Numerical and experimental analysis of a wood drying process, Int. Commun. Heat Mass., 37, 756-760, doi:10.1007/s002260000083, 2010.

Toro, S., Sanchez, P., Blanco, P., de Souza Neto, E., Huespe, A., and Feijao, R.: Multiscale formulation for material failure accounting for cohesive cracks at the macro and micro scales, Int. J. Plasticity, 76, 75-110, doi:10.1016/j.ijplas.2015.07.001, 2016.

Ward, C. R.: Analysis and Significance of Mineral Matter in Coal Seams, Int. J. Coal Geol., 50, 135-168, doi:10.1016/S01665162(02)00117-9, 2002.

Wei, R., Zhou, K., Keer, L. M., and Fan, Q.: Modeling surface pressure, interfacial stresses and stress intensity factors for layered materials containing multiple cracks and inhomogeneous inclusions under contact loading, Mech. Mat., 92, 8-17, doi:10.1016/j.mechmat.2015.08.008, 2016.

Wetherall, K., Moss, R., Jones, A., Smith, A., Skinner, T., Pickup, D., Goatham, S., Chadwick, A., and Newport, R.: Sulfur and iron speciation in recently recovered timbers of the Mary Rose revealed via X-ray absorption spectroscopy, J. Arch. Sci., 35, 1317-1328, doi:10.1016/j.jas.2007.09.007, 2008.

Zadin, V., Kasemagi, H., Valdna, V., Vigonski, S., Veske, M., and Aabloo, A.: Application of multiphysics and multiscale simulations to optimize industrial wood drying kilns, Appl. Mat. Comput., 267, 465-475, doi:10.1016/j.amc.2015.01.104, 2015. 